\title{
Application of Radial Basis Functional Link Networks to Exploration for Proterozoic Mineral Deposits in Central Iran
}

\author{
Pouran Behnia ${ }^{1,2}$
}

ERRATUM TO: NATURAL RESOURCES

RESEARCH, VOL. 16, NO. 2, JUNE 2007

DOI: 10.1007/S11053-007-9036-7

The incorrect version of Figure 4 was inadvertently placed in the article. The correct version follows on the next page.

\footnotetext{
${ }^{1}$ Geomatics Department, Geological Survey of Iran, Tehran, Iran.

${ }^{2}$ To whom correspondence should be addressed; e-mail: pouranb @yahoo.com

The online version of the original article can be found under doi: 10.1007/s11053-007-9036-7.
} 

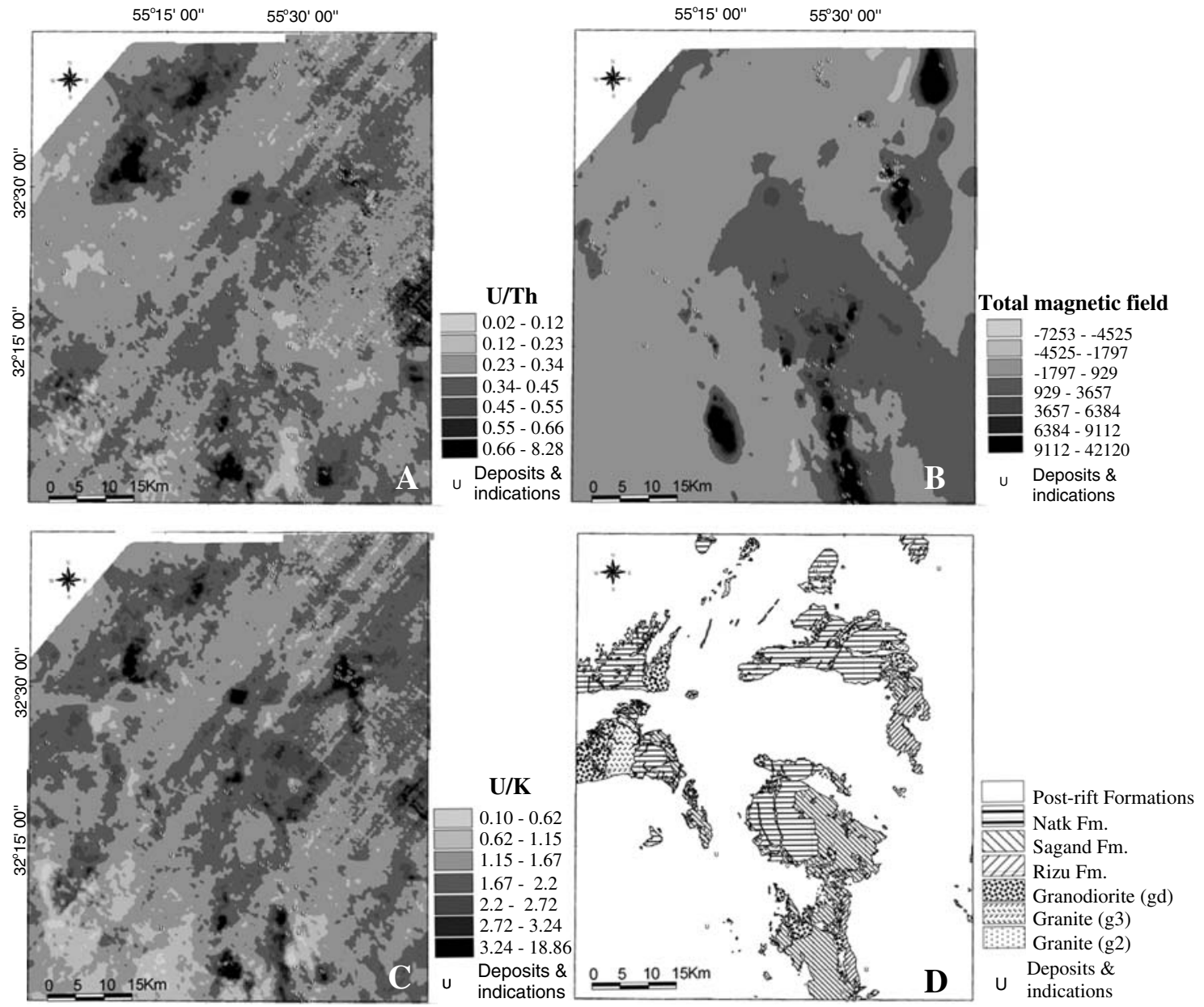

Fig. 4. Multi-class predictive patterns of U/Th ratio (A), total magnetic field (B), U/K ratio (C), and geology (D). 